УдК 364.2:330.59

\title{
КРИТЕРИИ СОЦИАЛЬНОГО БЛАГОПОЛУЧИЯ: УНИВЕРСАЛИЗМ И ПРОБЛЕМЫ СОЦИОКУЛЬТУРНОГО ИЗМЕРЕНИЯ
}

\author{
Петренко Максим Степанович1,2, \\ petmaxim@yandex.ru \\ Дукарт Сергей Александрович ${ }^{3-5}$, \\ dukart@mail.ru \\ 1 Новосибирский государственный университет экономики и управления, \\ Россия, 630099, г. Новосибирск, ул. Каменская, 52/1. \\ 2 Новосибирский юридический институт (филиал) \\ Томского государственного университета, \\ Россия, 630099, г. Новосибирск, ул. Советская, 7. \\ ${ }^{3}$ Национальный исследовательский Томский политехнический университет, \\ Россия, 634050, г. Томск, пр. Ленина, 30. \\ 4 Томский государственный университет систем управления и радиоэлектроники, \\ Россия, 634050, г. Томск, пр. Ленина, 40. \\ 5 Российский государственный университет правосудия, \\ Россия, 634050, г. Томск, пл. Ленина, 2.
}

Петренко Максим Степанович, кандидат исторических наук, доцент кафедры мировой экономики, международных отношений и права Новосибирского государственного университета экономики и управления; доцент кафедры общественных наук Новосибирского юридического института (филиала) Томского государственного университета.

Дукарт Сергей Александрович, кандидат исторических наук, доцент отделения социальногуманитарных наук Школы базовой инженерной подготовки Национального исследовательского Томского политехнического университета; доцент кафедры экономики экономического факультета Томского государственного университета систем управления и радиоэлектроники; доцент кафедры гуманитарных и социально-экономических дисциплин Российского государственного университета правосудия.

Статья посвящена проблеме поиска критериев социального благополучия и выработке методологических принципов изучения данного явления. Актуальность исследования социального благополучия обусловлена сложившейся в современном обществе системой приоритетов, их нацеленностью на повышение качества жизни и решение социальных проблем. Слабая разработанность понятия благополучия, неоднозначность оценок, существование различных подходов к пониманию данного явления, множественность теоретических моделей определяют актуальность настоящего исследования и в научном плане. Цель работы: проанализировать сложившиеся в социальноэкономических и психологических областях знания подходы к выявлению критериев социального благополучия, дать их критическую оценку, наметить пути решения проблемы. Методы: аналитический и компаративный методы исследования, позволившие сравнить объективистский подход к изучению социального благополучия с субъективным. Результаты. Сравнительный анализ сложившихся в научной среде позиций позволил обнаружить недостаточность как социальноэкономического, так и психологического понимания социального благополучия. Сделан вывод об ограниченности универсалистских критериев социального благополучия и необходимости их дифференциации с учетом влияния социокультурных и исторических факторов, а также групповой принадлежности индивидов. Выявлена важная роль идентичности и эстетического выбора личности 
в формировании ее потребностей и определении значимого как критерия социального благополучия, которое закрепляется на путях легитимации группой сделанного индивидом выбора.

Ключевые слова: Социальное благополучие, благосостояние, потребности, ценности, идентичность.

Вопросы социального благополучия приобретают все большее значение в современном мире. Тратятся огромные средства на борьбу с бедностью, поддержку инвалидов, преодоление дискриминационных практик в отношении лиц, не имеющих возможности выбирать свой социальный статус по полу, возрасту, расе, национальности и пр. Однако поставив во главу угла задачу повышения качества жизни, национальные правительства и международные организации, по сути, оставили открытым вопрос, что же считать благополучием и по каким критериям его измерять.

Усилия социально ориентированных государств традиционно направлены в сторону проведения мероприятий социально-экономического характера. Выплата социальных пособий, предоставление льгот для инвалидов, молодежи, лиц преклонного возраста, увеличение продолжительности отпусков, сокращение рабочего дня, развитие образования и здравоохранения, борьба с преступностью - вот неполный перечень тех действий, которые совершает правительство, стремящееся повысить уровень благополучия своих граждан.

Поскольку уровень развития стран неодинаков, сама постановка вопроса о благополучии сталкивается с проблемой относительности суждений. Благополучие определенной социальной группы в центральноафриканских странах может не восприниматься таковым в Европе. Поэтому перед экспертами встал вопрос разработки ключевых понятий и инструментов измерения для сравнения разных стран мира. Пожалуй, наибольшей известностью в этом отношении пользуется так называемая концепция «человеческого развития» (Human Development Project). При анализе уровня благополучия она выходит за рамки материальных показателей и обращается к таким вопросам, как социальное равенство, социальные, экономические и политические возможности.

В своих докладах о человеческом развитии международные эксперты используют несколько индексов измерения:

- Индекс развития человеческого потенциала ООН (Human Development Index HDI), включающий суммарные измерения человеческого развития.

- Индекс лучшей жизни (OESD Better Life Index), учитывающий жилищные условия, доход, работу, образование, здоровье, гражданские права, безопасность и пр.

- Глобальный индекс благополучия (Gallup-Healthways), включающий пять основных аспектов (успех, социальное, финансовое, физическое и общественное благополучия) и измеряемый по пятибалльной шкале;

- Всемирный индекс счастья (Нарpy Planet Index - HPI), основные компоненты которого: ожидаемая продолжительность жизни, опыт благополучия и экологический след;

- Индекс процветания (Prosperity Index), вычисляемый на основе 89 различных показателей, которые отбираются путем анализа 8 аспектов (экономика, бизнес, управление, образование, здоровье, безопасность, личные свободы, социальный капитал);

- Индекс социального прогресса (Social Progress Index), выделяющий три аспекта благополучия (основные потребности человека, основы благополучия и возможности);

- Национальные расчеты благополучия (National accounts of well-being), в котором выделяют индивидуальное благополучие (эмоциональное благополучие, удовлетворенность жизнью, жизненная энергия, жизнестойкость и самооценка, позитивное 
функционирование) и социальное благополучие (поддерживающие взаимоотношения, доверие и принадлежность) [1].

Налицо ориентация специалистов на так называемые объективные, универсальные критерии благополучия, в основе которых лежит убежденность, что счастье человеческое определяется рядом известных факторов (безопасность, здоровье, экология, развитая инфраструктура, материальный достаток, возможность самореализации и т. д.). Положительное решение этих задач позволяет повышать уровень и качество жизни, что в обязательном порядке должно вести к росту социального благополучия. Если же общество недовольно, необходимо выяснить, какие из внешних факторов, обеспечивающих социальный комфорт, отсутствуют или недостаточно развиты, чтобы затем, сосредоточившись на создании благоприятных социально-экономических условий, повысить уровень благополучия населения. Например, в Декларации тысячелетия 2015 г., подготовленной в рамках борьбы ООН с бедностью, прямо говорится о восьми целях, достижение которых позволит решить главные социальные проблемы:

- ликвидация крайней нищеты и голода;

- обеспечение всеобщего начального образования;

- поощрение равенства мужчин и женщин, расширение прав и возможностей женщин;

- сокращение детской смертности;

- улучшение охраны материнства;

- борьба с ВИЧ/СПИДом, малярией и другими заболеваниями;

- обеспечение экологической устойчивости;

- формирование глобального партнерства в целях развития [2].

При этом идет спор о количественных характеристиках благополучия населения: каков должен быть минимальный уровень дохода одного человека, сколько денег следует расходовать на содержание одного заключенного, чтобы не переступить черту гуманности и т. п. Например, в 2015 г. Всемирный банк установил глобальный уровень бедности в размере 1,90 долларов США в день [3], что должно быть своеобразным ориентиром правительствам в борьбе с нищетой.

Таким образом, вопрос благополучия фактически сводится к оценке уровня жизни населения, которая дается сквозь призму трех основных характеристик:

1. Благосостояние населения, которое рассматривается с точки зрения уровня потребления, степени дифференциации населения по уровню дохода относительно некоего установленного жизненного стандарта.

2. Накопление человеческого капитала, под которым понимается здоровье населения, уровень развития образования, культуры, профессиональные навыки в контексте способностей к воспроизводству общества и человека как социально-экономического субъекта.

3. Уровень человеческого развития, который включает возможности самореализации человека как личности. Здесь выделяются два аспекта:

а) качество жизни, подразумевающее экологические, демографические, интеллектуальные и прочие условия существования и самореализации личности;

б) интеграция индивида (участие в самоуправлении, возможность влияния на политические процессы, наличие или отсутствие дискриминации в отношении тех или иных социальных групп и т. п.).

Согласно исследованиям Института народнохозяйственного прогнозирования РАН выделяются следующие индикаторы измерения уровня жизни населения: 
- ВВП на душу населения. Доля расходов на конечное потребление домашних хозяйств в ВВП;

- уровень реальных доходов населения; уровень реальной заработной платы и пенсий;

- показатели распределения населения по уровню среднедушевого дохода (в частности, децильный коэффициент фондов, характеризующий соотношение среднедушевых доходов 10 \% населения с наибольшими и наименьшими доходами);

- общий уровень потребления материальных благ и услуг, в том числе по продуктам питания, алкогольным напиткам, предметам гардероба, товарам длительного пользования и хозяйственного назначения, услугам;

- белково-калорийная ценность суточного рациона питания (потребление калорий, белков, жиров и углеводов на душу населения в сутки);

- обеспеченность жильем и основными предметами длительного пользования (на 1 семью / домашнее хозяйство и одного человека);

- ожидаемая продолжительность жизни у мужчин и женщин; младенческая смертность;

- общий уровень безработицы (число безработных и их доля в численности экономически активного населения); безработица среди молодежи (с 16 до 24 лет);

- доля государственных расходов на образование и здравоохранение в ВВП;

- обеспеченность населения услугами здравоохранения (число врачей и больничных коек на 10000 чел.) ;

- образовательный уровень населения (численность учащихся начальных и средних общеобразовательных школ, студентов вузов на 10000 чел.) [4].

Приведенные формулировки и количественные характеристики наглядно демонстрируют стремление свести проблему изучения благосостояния человека к анализу внешних социальных факторов. Другими словами, если мы увеличим число врачей, количество студентов, повысим долю государственных расходов на образование и здравоохранение, то теоретически мы повысим уровень благосостояния общества и каждого человека в отдельности. Большинство социально-экономических исследований, посвященных анализу проблем социального благополучия, построено именно по этой схеме. Даже если ученые пытаются выйти за рамки использования ВВП как главного показателя уровня жизни, они тем не менее настойчиво ищут универсальные критерии измерения благополучия, поддающиеся эмпирической проверке [5].

Попытки западных специалистов в области экономической психологии учитывать самооценочные показатели полезности также не позволили им выйти за рамки убежденности о решающем влиянии внешних факторов (доход, уровни инфляции и безработицы и пр.) на благополучие личности [6]. Приверженность универсализму и поиск нужных индексов прочно закрепился в социально-экономических исследованиях. Достаточно посмотреть официальные отчеты. Например, департамент по вопросам информационно-аналитического обеспечения Центрального федерального округа Российской Федерации в своем мониторинге социального благополучия в ЦФО прямо называет три основных критерия благополучия - материальное благосостояние, здоровье и безопасность - и приводит многочисленные диаграммы, свидетельствующие о доходах населения, расходах на здравоохранение, образование, распространение алкоголизма, число преступлений и т. п. [7]. Так же выглядят отчеты на Западе [8, 9].

Воззрения такого рода представляются несколько наивными и грешат излишней отвлеченностью. Возникает своеобразный разрыв между официально декларируемыми заявлениями и реальным положением дел, когда граждане не чувствуют на себе повы- 
шения уровня жизни, даже когда им заявляют, что количество квадратных метров жилья в стране возросло. О существовании расхождений между объективными характеристиками и восприятием реальности населением справедливо пишут Н.В. Гоффе и Г.А. Монусова, которые убедительно показали, как ловушки искаженного восприятия влияют на формирование представлений социального благополучия [10]. К тому же не следует сводить такое состояние, как благополучие, к одному лишь благосостоянию. Благополучие - преимущественно оценочное понятие, и поэтому в значительной степени субъективное. Следовательно, и рассматривать его надо на основе субъективного подхода.

Проблема благополучия ни в коем случае не может быть сведена к оценке «хорошо» или «плохо». Когда мы имеем дело с субъективной стороной восприятия, особенно повседневной жизни, следует учитывать, что психологически переживаемое состояние комфорта, уюта, благополучия не рефлексируется нашим сознанием, поскольку не обладает дискретностью. Явления в потоке жизни не вычленяются сознанием и потому незначимы. Только прервавшись, утратив свою привычную комфортность, субъективно переживаемое ощущение благополучия может быть до конца осознано (и как состояние прошедшее). Чаще всего рефлексируется дискомфорт, потому что он изначально предполагает дискретность, расщепленность, прерывание потока жизни. Отсюда преобладание критического отношения к действительности, постоянная неудовлетворенность, когда мы порой не ценим, что имеем.

Восприятие реальности, внешних условий, которые, безусловно, влияют на наше ощущение благополучия, существенно различается у разных категорий населения, не говоря уж об отдельных этнических, религиозных группах, населениях стран, имеющих разное историческое прошлое или разделенных по времени. Картина мира, задающая во многом субъективные критерии благополучия, сложившаяся в Античности, значительно отличается от мировоззрения средневекового человека, как и человека нашего времени. Поэтому сам поиск внешних универсальных критериев социального благополучия, разработка формальных индикаторов уровня жизни представляются ограниченными, поскольку исходят из абстрактной модели человека. Рассмотрение индивида вне группы, вне социума невозможно. Взятый в аспекте социальных качеств человек как личность обязательно выступает и обнаруживает себя через принадлежность к той или иной группе. Он итальянец, христианин, ремесленник, мужчина, рыбак и т. д. Утверждать факт существования в обществе универсальных ценностей и предпочтений значит сознательно упрощать реальность, игнорировать многообразие форм и культурных практик, конструировать лишь одну субъективно «правильную» систему ценностей - как более предпочтительную по отношению ко всем остальным. За этим, по сути, кроется стремление загнать всех, кто мыслит иначе, в «прокрустово ложе» лишь одной системы координат, что противоречит универсалистским принципам защиты прав человека и неизбежно порождает репрессивную систему ценностей.

Является ли, например, положение женщины в исламских фундаменталистских странах дискриминационным и, следовательно, неблагополучным? С точки зрения универсальных критериев, выдвинутых европоцентристским сознанием, безусловно, да. Чтобы преодолеть это состояние, общества, в которых положение дел с правами женщин обстоит благополучно, станут направлять дополнительные средства на поддержку женщин, оказавшихся жертвами социальной дискриминации, поощрять тех, кто найдет в себе силы порвать с традиционной культурой. Международные организации будут давать премии борцам с фундаментализмом, чьи усилия по разрушению привычного для миллионов людей уклада жизни имеют все шансы добиться поставленной це- 
ли. Однако возрастет ли благополучие людей, которых лишили укорененного общественного уклада и поместили в чуждую им культурную среду социальных практик, основанных на толерантности, политкорректности, уважении прав сексуальных меньшинств и т. п.? Есть все основания сомневаться в положительном ответе на этот вопрос, если, конечно, мы не исходим из универсальных критериев благополучия. Любая попытка игнорировать исторически сложившиеся культурные стандарты и практики неизбежно приведет к сопротивлению со стороны значительной части общества. Ввергнутое в пучину острого социального противостояния, раздираемое стимулируемыми извне внутренними противоречиями, такое общество вряд ли можно будет назвать благополучным.

Другими словами, объективистский подход к анализу проблем благополучия не только ущербен с познавательной точки зрения, но и содержит опасность оправдания насилия по отношению к тем социальным группам и даже целым народам, которые в ходе исторического развития выработали свою, отличную от других систему ценностей и приоритетов.

Универсальные критерии благополучия (уровень дохода, образования, отсутствие дискриминации, доступ к участию в политических делах и т. д.) по определению являются социальными критериями. При этом зачастую упускается из виду тот факт, что сам по себе источник социального находится в человеческом разуме. Чтобы критерий или явление были социальными, они должны быть значимыми. Отделение же значимого от незначимого, как и весь мир смыслов, создается в рамках культуры. Поэтому рассматривать критерии благополучия вне рамок конкретных культур нелепо.

Обращение к субъективным критериям благополучия неизбежно толкает нас в сторону психологии. Именно в этой области научного знания были разработаны фундаментальные концепции и модели, проведены многочисленные эмпирические исследования, позволившие лучше понять основные факторы социального благополучия. Причем нельзя сказать, что психологи игнорируют внешние обстоятельства или рассматривают личность вне общества. Большинство ученых принимает во внимание как частные, так и социальные факторы благополучия. Если в рамках гедонистического подхода, теоретические основы которого заложил Н. Бредбёрн, источник психологического благополучия виделся преимущественно в накоплении удовольствий и установлении своеобразного баланса между позитивными и негативными эмоциями [11], то эвдемонистический подход в изучении субъективного благополучия уже четко установил, что главный и самый необходимый аспект благополучия - личностный рост.

Учет социального, внешнего по отношению к индивиду стал как бы обязательным условием современных психологических концепций благополучия. Примером могут служить исследования К. Кейса, который выделил пять измерений социального благополучия: социальная интеграция, общественный вклад, социальная согласованность, социальная актуализация и общественное признание [12]. Однако, пожалуй, наибольшую популярность в этой сфере приобрела известная американская исследовательница в области психологии благополучия К. Рифф, которая выделила шесть отдельных компонентов позитивного психологического функционирования личности. Это хорошее самочувствие, которое включает в себя положительные оценки себя и своей прошлой жизни (Самопринятие); чувство постоянного роста и развитие себя как личности (Рост); веру в то, что жизнь является целенаправленной и значимой (Цель в жизни); обладание качественными отношениями с окружающими (Позитивные отношения с другими); способность эффективно управлять своей жизнью и окружающим миром (Мастерство); чувство самоопределения (Автономия) [13]. 
Это лишь самые основные подходы в изучении субъективного благополучия, перечисление которых можно было бы продолжить. Исследователь Б.Е. Пахоль, например, насчитал 13 теоретических моделей психологического благополучия [14]. Однако при всей своей фундаментальности, добросовестно проведенных массовых опросах, социально-психологические исследования феномена благополучия также тяготеют к выявлению общих признаков и универсальных критериев психологического здоровья, поиску общей тенденции. Сам факт различий отдельных социальных групп невольно игнорируется за некоторым исключением. Чаще всего дифференциация благополучия сводится лишь к выделению отдельных категорий населения, различающихся по полу или возрасту.

Вместе с тем следует учитывать и социокультурные факторы, задающие в разные эпохи, в разных странах свои критерии благополучия. Культурная среда во многом определяет систему идеалов, которая содержится в концентрированном виде не только в священных текстах и изречениях великих людей, но и в беллетристике, кинематографе, повседневных практиках. При этом не следует преувеличивать влияние внешней культурной среды. Социокультурные установки скорее задают общий тон, предрасположенность, направление, по которому идет формирование субъективных представлений о счастье и благополучной жизни. Индивидуальные установки не являются жестко детерминированными социальной средой и культурой. Вместе с тем они не носят и произвольный характер, поскольку действие индивида в обществе всегда имеет внешнее выражение и ориентировано на других людей.

Культура и социальность инкорпорированы в человека и во многом предопределяют его индивидуальные практики, нацеленные в конечном счете на достижения благополучия, как индивидуального, так и социального. П. Бурдье, пытаясь примерить детерминизм с волюнтаризмом, разрабатывая теоретическую основу для группового размежевания, широко использовал понятие габитуса (укорененных диспозиций, предрасположенностей), который развивается по принципу самопрограммирующейся программы. У габитуса есть свои детерминанты: ный);

- капитал (не только экономический, но и социальный, политический, культур-

- позиция в отношениях производства (например, определенная через профессию, род занятий со всеми сопутствующими детерминациями);

- тип социальной связи, в которую человек включен;

- история группы, к которой принадлежит индивид;

- индивидуальная история (биография) [15, с. 39].

Указанные факторы задают лишь общие критерии, по которым можно дифференцировать социальные группы, различающиеся своим пониманием значимого. При этом важную роль в социальном размежевании и обеспечении благополучия играет идентификация индивида и его эстетический выбор. К. Дей и А. Кингтон, изучив 100 школ Англии, подтвердили существование прочной связи между идентичностью, благополучием и эффективностью профессиональной деятельности учителей. Причем на стабильность или фрагментацию идентичности влияют как личные, так и профессиональные факторы [16]. Речь не идет исключительно о социально-классовой, профессиональной, религиозной или национальной идентичности. Сам принцип, по которому вырабатываются критерии для разграничения сообществ, может быть одной из специфических особенностей группы, которая вычленяет себя по основанию, незначимому в глазах других социальных общностей. 
Поскольку идентичность является важным основанием совершаемого выбора, постольку обеспечение социального благополучия в обществе невозможно без реализации потребности личности в демонстрации групповой принадлежности. Утрата индивидом чувства коллективного «мы» не менее трагически сказывается на человеке, чем потеря самого себя. Поэтому идентификация оказывает решающее влияние на потребности и предпочтения людей, их ценности, нормы, критерии значимого и т. п. Сильная социальная идентичность сама по себе является мощным фактором счастья [17]. Социальные группы выступают важным психологическим ресурсом, способным защищать здоровье и благополучие, но они эффективны лишь тогда, когда идентичность, разделяемая с другим человеком или группой, признается окружающими [18]. Медицинские и психологические исследования показали, чем больше у человека друзей, чем выше привязанность к семье или клубам, тем лучше его физическое здоровье [19].

Говоря об идентичности как факторе благополучия, следует учитывать двойственный характер идентичности: идентичность как отождествление себя с кем-то и идентичность как индивидуальность, как утверждение собственной уникальности, как сохранение верности самому себе. Второй компонент идентичности не менее важен, чем первый. Ощущение благополучия невозможно в ситуации раздвоения или отчуждения личности. Выбор, сделанный под давлением внешне привлекательной для индивида группы, но не находящий глубинного отклика в душе, может привести к психологическому дискомфорту, когда говорить о социальном благополучии уже не приходится. Такое положение вещей можно обнаружить сплошь и рядом, когда мы имеем дело с навязанными извне ценностями.

В этом отношении благополучие социально детерминировано. Но не в смысле существования независимых от человека и его группы универсальных факторов, направляющих его жизнь к лучшему, а в плане обязательных для человека практик легитимации сделанного им выбора в пользу тех или иных значимых для него критериев благополучия. Группа, которую мы выбираем, должна узаконить сделанный выбор значимого как критерия благополучия. В противном случае будет осуществлена замена выбранной группы.

П. Бурдье утверждал, что социальная идентичность утверждается в различиях и реализуется в опыте [20]. При этом особое значение ученый придавал стилю жизни и вкусу, которые символически выражают занимаемые индивидом классовые позиции и позволяют отличать одну группу от другой. Например, противопоставляя группы с разными доходами, П. Бурдье утверждал, что если для среднего класса потребность «казаться», в том числе в одежде и еде, то низшие классы тяготеют к тому, чтобы «быть». Поэтому естественность, непосредственность, простота как выбор низов противопоставляются П. Бурдье позерству, притворству, жеманству, манерности и церемонности верхов [20].

В этом отношении на первый план выступает эстетический выбор, который тесно связан с выбором идентичности. Потребности, удовлетворение которых выступает непременным условием социального и личного благополучия, нельзя сводить к базовым. Средние и высшие страты ориентированы на удовлетворение статусных потребностей. Но проблема не только в социально-классовой дифференциации. Стиль жизни, практики потребления, выбор форм проведения досуга во многом определяются эстетическими предпочтениями, которые не всегда соответствуют общепризнанным стандартам, особенно когда мы имеем дело с молодежными субкультурами. Обеспечение благополучия современных фриков, геймеров, хикикомори и др. вряд ли возможно на основе предоставления в их пользование всех благ цивилизации. Эстетическая оценка оказы- 
вает сильное влияние на когнитивное и эмоциональное состояние, способствуя физическому и психологическому благополучию. Современные исследования в области нейроэстетики подтверждают, что положительный эмоциональный эффект, полученный в результате эстетического опыта, влияет на настроение и косвенно способствует здоровью и благополучию [21].

Таким образом, универсализм и поиск объективно существующих параметров благополучия существенно сужает понимание природы изучаемого явления и сводит весь комплекс практической деятельности по повышению качества жизни к набору стандартных мероприятий без учета культурологических факторов и психологических особенностей людей, различающихся как по своим индивидуальным характеристикам, так и групповой принадлежности. При этом важную роль в формировании потребностей, удовлетворение которых служит условием обеспечения благополучия и основанием для группового размежевания, играют идентификация личности и ее эстетический выбор.

\section{СПИСОК ЛИТЕРАТУРЫ}

1. Кислицына О.А. Измерение качества жизни/благополучия: международный опыт. - М.: Ин-т экономики РАН, 2016. - 62 с.

2. Мы можем покончить с нищетой. Цели в области развития после 2015 года. URL: https://www.un.org/ru/millenniumgoals/ (дата обращения 22.07.2019).

3. Обновленные сведения о глобальном уровне бедности // Всемирный банк. URL: https://www.vsemirnyjbank.org/ru/topic/poverty/brief/global-poverty-line-faq (дата обращения 22.07.2019).

4. Уровень жизни населения: понятия, индикаторы, ситуация в России (аналитический материал Центра макроэкономического анализа и краткосрочного прогнозирования ИНП PAH). URL: http://www.forecast.ru/_ARCHIVE/PROJECTS/URG/URG.pdf (дата обращения 22.07.2019).

5. Павлова И.А., Гуменников И.В., Монастырный Е.А., Шарма Д. Что стоит за интегральными индексами благополучия? // Вестник науки в Сибири. - 2018. - № 4. - С. 230-254.

6. Dolan P., Peasgood T., White M. Do we really know what makes us happy? A review of the economic literature on the factors associated with subjective wellbeing // Journal of Economic Psychology. - 2008. V. 29. - P. 94-122. URL: https://pauldolan.co.uk/wp-content/uploads/2011/07/do-we-really-know-whatmakes-us-happy.pdf (дата обращения 25.07.2019).

7. Рейтинг социального благополучия регионов Центрального федерального округа. 1/2013. URL: http://cfo.gov.ru/media/files/41d48b0fba6f96dd9ddf.pdf (дата обращения 22.07.2019).

8. Compendium of OECD Well-Being Indicators. 2011. URL: http://www.oecd.org/sdd/47917288.pdf (дата обращения 23.07.2019).

9. Regional indicators of socioeconomic well-being. Research note. - 2016. - № 9. URL: https://ec.europa.eu/social/BlobServlet?docId=17480\&langId=en (дата обращения 22.07.2019).

10. Гоффе Н.В., Монусова Г.А. Социальное благополучие: восприятие реалий // Южно-российский журнал социальных наук. - 2018. - Т. 19. - № 3. - С. 21-36.

11. Bradburn N. The Structure of Psychological well-being. - Chicago: Aldine Pub. Co., 1969. - 320 p. URL: https://www.norc.org/PDFs/publications/BradburnN_Struc_Psych_Well_Being.pdf (дата обращения 23.07.2019).

12. Keyes C.L.M. Social Well-Being // Social Psychology Quarterly. - 1998. - V. 61. - № 2. - P. $121-140$. URL: https://langleygroupinstitute.com/wp-content/uploads/Lee-Keyes-2013-Social-Well-Being.pdf (дата обращения 23.07.2019).

13. Ryff C.D. Psychological well-being in adult life // Current Directions in Psychological Science. - 1995. V. 4. - № 4. - P. 99-104. URL: https://lemosandcrane.co.uk/resources/RISE\%20psychological\%20 wellbeing\%20in\%20adulthood.pdf (дата обращения 25.07.2019).

14. Пахоль Б.Е. Субъективное и психологическое благополучие: современные и классические подходы, модели и факторы // Украинский психологический журнал. - 2017. - № 1 (3). - С. 80-104.

15. Козлова Н.Н. Социально-историческая антропология. - М.: Ключ-С, 1998. - 156 с.

16. Day C., Kington A. Identity, well-being and effectiveness: the emotional contexts of teaching // Pedagogy Culture and Society. - 2008. - V. 16. - P. 7-23. 
17. De Oliveira D., Pankalla A., Cabeccinhas R. Ethnic Identity as predictor for the well-being: An exploratory transcultural study in Brazil and Europe // Summa Psicológica. - 2012. - V. 9. - № 2. - P. 33-42.

18. How Groups Affect Our Health and Well-Being: The Path from Theory to Policy / J. Jetten, C. Haslam, S.A. Haslam, G. Dingle // Social Issues and Policy Review. - 2014. - V. 8. - № 1. - P. 103-130.

19. The social cure: Identity, health and well-being / Eds. J. Jetten, C. Haslam, S.A. Haslam. - New York: Psychology Press, 2012. - 408 p.

20. Бурдье П. Различение: социальная критика суждения // Экономическая социология. - 2005. - Т. 6. № 3. - C. 25-48.

21. Mastandrea S., Fagioli S., Biasi V. Art and psychological well-being: Linking the brain to the aesthetic emotion // Frontiers in Psychology. - 2019. - Vl. 10. URL: https://www.frontiersin.org/articles/10.3389/ fpsyg.2019.00739/full (дата обращения 25.07.2019).

Поступила 29.07.2019 2. 
UDC 364.2:330.59

\title{
CRITERIA OF SOCIAL WELL-BEING: UNIVERSALISM AND PROBLEMS OF SOCIO-CULTURAL DIMENSION
}

\author{
Maxim S. Petrenko1,2, \\ petmaxim@yandex.ru \\ Sergei A. Dukart3-5, \\ dukart@mail.ru \\ 1 Novosibirsk State University of Economics and Management, \\ 52/1, Kamenskaya street, Novosibirsk, 630099, Russia. \\ 2 Novosibirsk Law Institute (branch) of Tomsk State University, \\ 7, Sovetskaya street, Novosibirsk, 630099, Russia. \\ 3 National Research Tomsk Polytechnic University, \\ 30, Lenin avenue, Tomsk, 634050, Russia. \\ 4 Tomsk State University of Control Systems and Radioelectronics, \\ 40, Lenin avenue, Tomsk, 634050, Russia. \\ 5 Russian State University of Justice, \\ 2, Lenin square, Tomsk, 634050, Russia.
}

Maxim S. Petrenko, Cand. Sc., associate professor, Novosibirsk State University of Economics and Management; associate professor, Novosibirsk Law Institute (branch) of Tomsk State University.

Sergei A. Dukart, Cand. Sc., associate professor, National Research Tomsk Polytechnic University; associate professor, Tomsk State University of Control Systems and Radioelectronics; associate professor, Russian State University of Justice.

This article is devoted to the problem of finding criteria for social well-being and development of methodological principles for studying this phenomenon. This study is relevant because the current system of priorities in modern society is aimed at improving the quality of life and solving social problems. The insufficient development of the concept of well-being, the ambiguity of assessments, the existence of different approaches to understanding this phenomenon, the multiplicity of theoretical models determine the relevance of this study in scientific terms. The aim of the study is to analyze the existing approaches of identifying the wellbeing in the socioeconomic and psychological areas of knowledge. It is supposed to give their critical assessment and outline ways to solve the problem. Methods. This article uses analytical and comparative methods to compare objectivist and subjective approaches to the study of social well-being. Results. A comparative analysis of the existing scientific positions revealed the insufficiency of socio-economic and psychological understanding of social well-being. The article makes a conclusion about the limitations of universalistic criteria of social well-being and the need for their differentiation, taking into account the influence of sociocultural and historical factors, as well as group belonging of individuals. It is important to note the role of identity and aesthetic choice of an individual in creating his/her needs and determining what is significant for him/her as a criterion of social well-being. The group's legitimation of the individual choice establishes the social nature of the criteria for well-being.

Key words: Social well-being, welfare, needs, values, identity.

\section{REFERENCES}

1. Kislitsyna O.A. Izmerenie kachestva zhizni/blagopoluchiya: mezhdunarodny opyt [Measuring quality of life/well-being: international experience]. Moscow, Institut ekonomiki RAN Publ., 2016. 62 p. 
2. My mozhem pokonchit s nishhetoy. Tseli v oblasti razvitiya posle 2015 goda [We can end poverty. Post 2015 Development Goals]. Available at: https://www.un.org/ru/millenniumgoals/ (accessed 22 July 2019).

3. Obnovlennye svedeniya o globalnom urovne bednosti. Vsemirny bank [The World Bank. Global Poverty Update]. Available at: https://www.vsemirnyjbank.org/ru/topic/poverty/brief/global-poverty-line-faq (accessed 22 July 2019).

4. Uroven zhizni naseleniya: ponyatiya, indikatory, situatsiya v Rossii (analiticheskiy material Tsentra makroekonomicheskogo analiza i kratkosrochnogo prognozirovaniya INP RAN) [The standard of living of the population: concepts, indicators, the situation in Russia (analytical material of the Center for Macroeconomic Analysis and Short-term Forecasting of the Institute of Economic Forecasting)]. Available at: http://www.forecast.ru/_ARCHIVE/PROJECTS/URG/URG.pdf (accessed 22 July 2019).

5. Pavlova I.A., Gumennikov I.V., Monastyrny E.A., Sharma D. What is behind composite wellbeing indices? Siberian journal of Science, 2018, no. 4, pp. 230-254. In Rus.

6. Dolan P., Peasgood T., White M. Do we really know what makes us happy? A review of the economic literature on the factors associated with subjective wellbeing. Journal of Economic Psychology, 2008, vol. 29, pp. 94-122. Available at: https://pauldolan.co.uk/wp-content/uploads/2011/07/do-we-really-know-whatmakes-us-happy.pdf (accessed 25 July 2019).

7. Reyting sotsialnogo blagopoluchiya regionov Tsentralnogo federalnogo okruga [Social well-being rating of the regions of the Central Federal District]. Available at: http://cfo.gov.ru/media/files/41d48b0fba6f96dd9ddf.pdf (accessed 22 July 2019).

8. Compendium of OECD Well-Being Indicators, 2011. Available at: http://www.oecd.org/sdd/47917288.pdf (accessed 23 July 2019).

9. Regional indicators of socioeconomic well-being. Research note, 2016, no. 9. Available at: https://ec.europa.eu/social/BlobServlet?docId=17480\&langId=en (accessed 22 July 2019).

10. Goffe N.V., Monusova G.A. Social well-being: perception of realities. Yuzhno-rossiiskiy zhurnal sotsialnykh nauk, 2018, vol. 19, no. 3, pp. 21-36. In Rus.

11. Bradburn N. The Structure of Psychological well-being. Chicago, Aldine Pub. Co., 1969. 320 p. Available at: https://www.norc.org/PDFs/publications/BradburnN_Struc_Psych_Well_Being.pdf (accessed 23 July 2019).

12. Keyes C.L.M. Social Well-Being. Social Psychology Quarterly, 1998, vol. 61, no. 2, pp. 121-140. Available at: https://langleygroupinstitute.com/wp-content/uploads/Lee-Keyes-2013-Social-WellBeing.pdf (accessed 23 July 2019).

13. Ryff C.D. Psychological well-being in adult life. Current Directions in Psychological Science, 1995, vol. 4, no. 4, pp. 99-104. Available at: https://lemosandcrane.co.uk/resources/RISE\%20psychological\% 20wellbeing\%20in\%20adulthood.pdf (accessed 25 July 2019).

14. Pakhol B.E. Subektivnoe i psikhologicheskoe blagopoluchie: sovremennye i klassicheskie podkhody, modeli i faktory [Subjective and psychological well-being: modern and classical approaches, models and factors]. Ukrainskiy psihologicheskiy zhurnal, 2017, no. 1 (3), pp. 80-104. Available at: http://borispakhol.net/files/2017/05/Pahol-B.E.-Subektivnoe-i-psihologicheskoe-blagopoluchiesovremennye-i-klassicheskie-podhody-modeli-i-faktory-2016-rus-vers.pdf (accessed 24 July 2019).

15. Kozlova N.N. Sotsialno-istoricheskaya antropologiya. [Socio-historical anthropology]. Moscow, Klyuch-S Publ., 1998. 156 p.

16. Day C., Kington A. Identity, well-being and effectiveness: the emotional contexts of teaching. Pedagogy Culture and Society, 2008, vol. 16, pp. 7-23.

17. De Oliveira D., Pankalla A., Cabeccinhas R. Ethnic Identity as predictor for the well-being: An exploratory transcultural study in Brazil and Europe. Summa Psicológica, 2012, vol. 9, no 2, pp. 33-42.

18. Jetten J., Haslam C., Haslam S.A., Dingle G. How Groups Affect Our Health and Well-Being: The Path from Theory to Policy. Social Issues and Policy Review, 2014, vol. 8, no 1, pp. 103-130.

19. The social cure: Identity, health and well-being. Eds. J. Jetten, C. Haslam, S.A. Haslam. New York, Psychology Press, 2012. 408 p.

20. Bourdieu P. Razlichenie: sotsialnaya kritika suzhdeniya [Distinction. Social critique of judgement]. Ekonomicheskaya sotsiologiya, 2005, vol. 6, no 3, pp. 25-48.

21. Mastandrea S., Fagioli S., Biasi V. Art and psychological well-being: Linking the brain to the aesthetic emotion. Frontiers in Psychology, 2019, vol. 10. Available at: https://www.frontiersin.org/articles/ 10.3389/fpsyg.2019.00739/full (accessed 25 July 2019). 